\title{
Study the effect of sample's chemical composition on the quality of gamma measurements using Mont-Carlo simulation
}

\author{
Wafaa F. Bakr
}

\begin{abstract}
Performing accurate relative measurements of sample's activities using a Hyper Pure Germanium detector (HPGe) necessitates the use of calibration standards. However, standards with similar characteristics like those of the measured samples are not usually available. This work aimed at studying the effect of variation in chemical compositions of measured samples on the accuracy of the gamma analysis used hyper purity germanium (HPGe) detector-based spectrometers. The Monte Carlo simulation technique is used to obtain the detector response due to four different standard soil samples. The samples were assumed to be identical except for chemical compositions and slight variations in densities. The simulation process involves the modeling of a HPGe detector for which the pulse height tally " $\mathrm{F8}$ " is calculated at different common gamma ray energy lines using the MCNP5 Code for the four samples. The analysis covered gamma energies ranged from 46.5 up to $1764.0 \mathrm{keV}$. The results showed that the effect of soil's chemical compositions is less than $\mathbf{0 . 5 \%}$ for gamma energy greater than 186.2.0 keV.
\end{abstract}

Index Terms - Efficiency calibration, chemical composition, HPGe detector, MCNP.

\section{INTRODUCTION}

Accurate radioactivity measurements of radioisotopes-bearing samples are usually performed using relative methods. In such methods the radiation emitted from the assayed samples are measured by utilizing a previously calibrated radiation detector using standard materials. Due to the wide variety of the assayed samples; typically calibration standards with identical characteristics to the assayed samples are not usually available. Consequently, the quality of measurement result is affected by the varied characteristics between the standard and the assayed samples. These characteristics may include the matrix material, sample geometry, density, material and shape of the container etc. Although most characteristics could be adapted to meet those of the standards, the chemical compositions of the assayed samples are still always different.

The analysis of radioactivity contents in environmental samples is widely carried out using high purity germanium (HPGe) detector-based gamma spectrometers. The specific activity $\mathrm{A}(\mathrm{Bq} / \mathrm{kg})$ of a radioactive isotope in a sample is determined by the following formula [1]

$$
A=\frac{s}{T d_{Y} \varepsilon m} \cdot C \cdot a
$$

W.F.Bakr, Quality control and quality assurance department, Egyptian nuclear and radiological regulatory authority, Cairo, Egypt, 01001387829

\author{
where; \\ $S$ : net count of the full energy beak for the isotope; \\ T: measuring life time ( $s$ ); \\ $I_{\gamma}:$ branching ratio of the measured gamma energy; \\ $\varepsilon$ : absolute full energy beak efficiency of the detector; \\ m: mass of the sample $(\mathrm{kg})$; \\ $C$ : coincidence summing correction factor; \\ a: attenuation correction factor.
}

The parameters S, $T, m$ and $C$ could be determined experimentally, while $\mathrm{I} \gamma$ is taken from a tabulated data [2]-[3]. There are several approaches to deal with the determination of the attenuation factors " $a$ ". It could be determined experimentally or calculated based on the known chemical composition and density of the sample material [4] Monte Carlo simulations, application of self-attenuation equation and the Debertin method [5] are examples of methods used in calculation of the self-attenuation correction factor.

The main element for mathematical calibration is the accurate knowledge of the physical and geometrical characteristics of the detector, such as length and diameter of the Ge crystal, thickness of the dead layer and features of other components (endcap, crystal holder, ... . ) [6] as well as the main knowledge of the container characteristics where the samples are packed and measured.

The idea in this work is to answer the question: to what extent the efficiency calibration curve generated using a certain certified sample for a HPGe detector could be successfully used to estimate the activity of isotopes in other samples having almost the same characteristics except for chemical compositions?. This question is essential in the sense that it will reduce the number of required calibration standards. This study is concerned with the evaluation of the effect of samples' chemical composition on the efficiency calibration of HPGe spectrometer.

The MCNP5 general Monte Carlo Code [7]-[8] is used to investigate the effect of the difference in samples chemical composition on the response of a radiation detector.

Efficiency calibration curves for a HPGe detector were generated for four different soil samples. The samples were assumed to have same geometry, volume, and container and located at the same position with respect to the detectors. The only difference is the chemical composition, and consequently they have relatively slight differences in densities. The analysis covered the gamma energies ranged from $46.5 \mathrm{keV}$ to $1764.0 \mathrm{keV}$. 


\section{II. .MONTE CARLO SimULATION}

\section{A. Modeled Samples}

Four different soil samples were modeled in this work. Three of them are IAEA reference standards indicated as RGU-1(ore), IAEA-357 (sediment) and soil-6 (soil), the fourth is a MCNP5 build-in sample indicated as dry U. S. Ave. The radioactivity contents in the IAEA samples are presented in Table (1) [9], while the material fractions in the samples are presented in Table (2) [10]-[11]. The identification numbers of the elements (ZAIDs) were listed in the material card of the MCNP input file with their weight fractions. The library identifiers were selected such that detailed physics interactions treatment was considered. The material densities are $1.23,1.19,1.287$ and $1.23 \mathrm{~g} / \mathrm{cm}^{3}$ for the RGU1, soli-6, IAEA-375 and built-in soil sample; respectively. All samples were modeled with the same volume $\left(70 \mathrm{~cm}^{3}\right)$ and configuration inside a plastic container. Figure (1) shows the shapes and dimensions of the modeled sample and container. Combination of truncated cones, planes and cylindrical surfaces were used to generate cells for sample and container.

Table (1) : Specific activity of radionuclide contents for the modeled reference samples

\begin{tabular}{|c|c|c|}
\hline Sample name & Isotope & $\begin{array}{c}\text { Certified activity } \\
(\mathrm{Bq} / \mathrm{kg})\end{array}$ \\
\hline IAEA-RGU-1 & $\mathrm{U}-238$ & 4960.0 \\
\hline \multirow{4}{*}{ IAEA-Soil 6 } & $\mathrm{Cs}-137$ & 53.65 \\
\cline { 2 - 3 } & $\mathrm{Ra}-226$ & 79.92 \\
\cline { 2 - 3 } & $\mathrm{Pu}-239+240$ & 1.04 \\
\cline { 2 - 3 } & $\mathrm{Sr}-90$ & 31.67 \\
\hline \multirow{5}{*}{ IAEA-375 } & $\mathrm{Am}-241$ & 0.13 \\
\cline { 2 - 3 } & $\mathrm{Cs}-134$ & 463.0 \\
\cline { 2 - 3 } & $\mathrm{Cs}-137$ & 5280.0 \\
\cline { 2 - 3 } & $\mathrm{I}-129$ & 0.0017 \\
\cline { 2 - 3 } & $\mathrm{K}-40$ & 424.0 \\
\cline { 2 - 3 } & $\mathrm{Pu}-238$ & 0.07 \\
\cline { 2 - 3 } & $\mathrm{Pu}-239+240$ & 0.3 \\
\cline { 2 - 3 } & $\mathrm{Ra}-226$ & 20.0 \\
\cline { 2 - 3 } & $\mathrm{Ru}-106$ & 56.0 \\
\cline { 2 - 3 } & $\mathrm{Sb}-125$ & 77.0 \\
\cline { 2 - 3 } & $\mathrm{Sr}-90$ & 108.0 \\
\cline { 2 - 3 } & $\mathrm{Th}-228$ & 21.0 \\
\cline { 2 - 3 } & $\mathrm{Th}-232$ & 20.5 \\
\cline { 2 - 3 } & $\mathrm{U}-234$ & 25.0 \\
\cline { 2 - 3 } & $\mathrm{U}-238$ & 24.4 \\
\hline
\end{tabular}

\section{B. Detector modeling}

The considered detector (ORTEC?? coaxial HPGe model GMX30P4-76, serial No. 50-TN32697A) was modeled according to the information provided by the manufacturer as illustrated in figure [2]. Plane, cylinder and sphere surfaces were used to construct the detector body, hole, holder, cap and Beryllium window. The rounded edges of the detector active volume and outer dead layer were constructed using combination of planes, cylindrical and tours surfaces. Figure (3) shows the model of the detector and sample created using the MCNP5 code.
Table (2): Material fractions in the selected samples

\begin{tabular}{|c|c|c|c|c|}
\hline \multirow{2}{*}{$\begin{array}{c}\text { Eleme } \\
\text { nt }\end{array}$} & \multicolumn{4}{|c|}{ Mass \% } \\
\hline & RGU-1 & Soil-6 & IAEA-375 & $\begin{array}{c}\text { Soil } \\
\text { MCNP }\end{array}$ \\
\hline $\mathrm{Si}$ & 46.4 & 17.96 & -- & 27.6 \\
\hline $\mathrm{O}$ & -- & 41.43 & -- & 51.34 \\
\hline $\mathrm{H}$ & -- & 0.95 & -- & -- \\
\hline $\mathrm{N}$ & -- & 0.64 & -- & -- \\
\hline As & -- & -- & 0.003 & -- \\
\hline $\mathrm{Ba}$ & -- & -- & 0.35 & -- \\
\hline $\mathrm{Br}$ & -- & -- & 0.005 & -- \\
\hline $\mathrm{U}$ & 0.04 & -- & 0.002 & -- \\
\hline $\mathrm{Al}$ & 0.1 & 5.07 & 46.95 & 6.7 \\
\hline $\mathrm{Fe}$ & 0.03 & 2.59 & 11.66 & 5.5 \\
\hline $\mathrm{Ca}$ & 0.03 & 16.35 & 15.13 & 5.0 \\
\hline $\mathrm{Na}$ & 0.02 & 0.42 & -- & -- \\
\hline $\mathrm{C}$, total & 0.01 & 11.46 & -- & -- \\
\hline $\mathrm{Mg}$ & 0.01 & 1.14 & -- & 1.3 \\
\hline $\mathrm{Pb}$ & 0.008 & -- & 0.022 & -- \\
\hline $\mathrm{K}$ & 0.002 & 2.41 & 15.60 & 1.4 \\
\hline $\mathrm{Ti}$ & 0.008 & 0.3 & -- & 0.45 \\
\hline$S$ & 0.002 & 0.28 & -- & -- \\
\hline $\mathrm{Th}$ & $<1 \mu \mathrm{g} / \mathrm{g}$ & -- & 0.54 & -- \\
\hline $\mathrm{Zn}$ & -- & -- & 0.026 & -- \\
\hline $\mathrm{Cd}$ & -- & -- & 0.028 & -- \\
\hline $\mathrm{Ce}$ & -- & -- & 0.041 & -- \\
\hline $\mathrm{Co}$ & -- & -- & 0.003 & -- \\
\hline $\mathrm{Cr}$ & -- & -- & 0.029 & -- \\
\hline Cs & -- & -- & 0.002 & -- \\
\hline $\mathrm{Cu}$ & -- & -- & 0.01 & -- \\
\hline $\mathrm{Eu}$ & -- & -- & $1.23 \mathrm{E}-05$ & -- \\
\hline Hf & -- & -- & 0.013 & -- \\
\hline $\mathrm{La}$ & -- & -- & 0.018 & -- \\
\hline $\mathrm{Lu}$ & -- & -- & 0.0002 & -- \\
\hline $\mathrm{Mn}$ & -- & -- & 0.204 & 0.07 \\
\hline $\mathrm{Na}$ & -- & -- & 4.61 & 0.6 \\
\hline $\mathrm{Nd}$ & -- & -- & 0.017 & -- \\
\hline $\mathrm{Ni}$ & -- & -- & 0.010 & -- \\
\hline $\mathrm{P}$ & -- & -- & 1.39 & -- \\
\hline $\mathrm{Rb}$ & -- & -- & 0.05 & -- \\
\hline $\mathrm{Sb}$ & -- & -- & 0.0003 & -- \\
\hline $\mathrm{Sc}$ & -- & -- & 0.004 & -- \\
\hline $\mathrm{Se}$ & -- & -- & 0.001 & -- \\
\hline $\mathrm{Sm}$ & -- & -- & 0.003 & -- \\
\hline $\mathrm{Sr}$ & -- & -- & 0.11 & -- \\
\hline $\mathrm{Ta}$ & -- & -- & 0.0006 & -- \\
\hline $\mathrm{Tb}$ & -- & -- & 0.0004 & -- \\
\hline $\mathrm{Tl}$ & -- & -- & 2.72 & -- \\
\hline $\mathrm{V}$ & -- & -- & 0.023 & -- \\
\hline$Y$ & -- & -- & 0.02 & -- \\
\hline $\mathrm{Yb}$ & -- & -- & 0.002 & -- \\
\hline $\mathrm{Zr}$ & -- & -- & 0.35 & -- \\
\hline
\end{tabular}




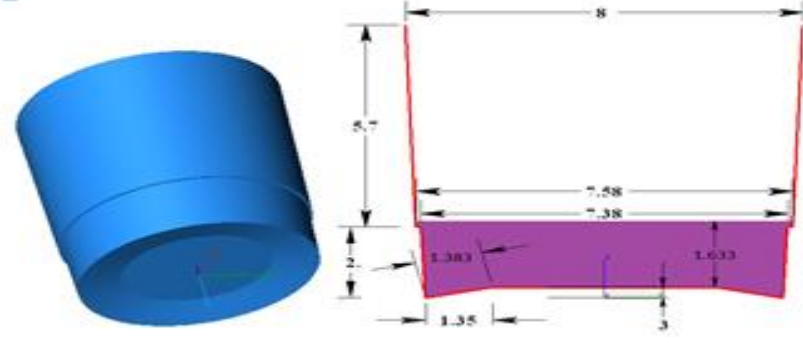

Fig. (1): shape and dimensions of the modeled sample.

\section{Efficiency calibration}

The absolute full energy peak efficiency of the detector was calculated at different gamma line energies for the four sources described above. The MCNP source card "sdef" was used with "cel", "rad" and "ext" keywords; and source information "si" card to define the source. Using this combination, the source was modeled as a volume with cylindrical shape that covers the active volume of the material with source efficiency of 0.4328 in the material sample. The pulse height tally "F8" (with energy bin card "e8") was used to estimate detector efficiency at eleven gamma lines with energies range between $46.5\left({ }^{210} \mathrm{~Pb}\right)$ and $1764.5\left({ }^{214} \mathrm{Bi}\right) \mathrm{keV}$ for each sample.

The number of simulated histories was determined so as to keep the uncertainties in Mote Carlo calculations always better than $0.2 \%$.

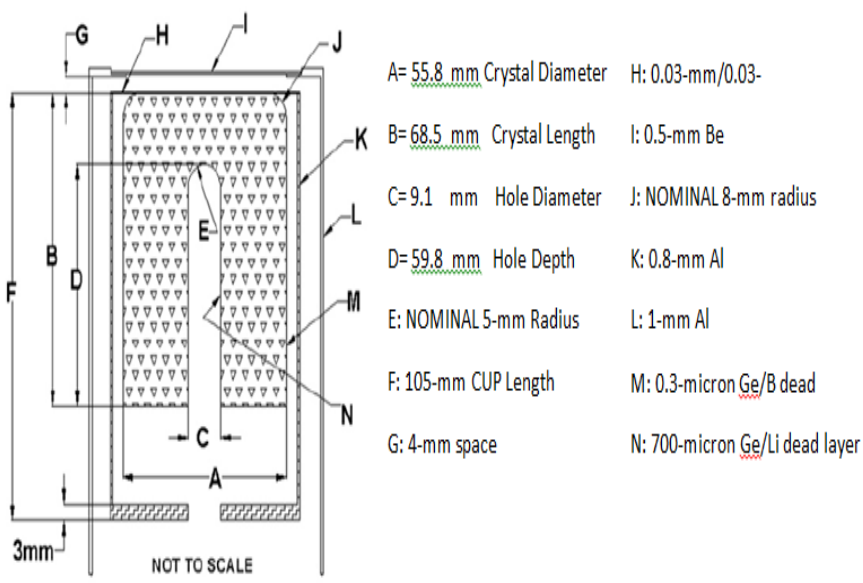

Fig. (2): Manufacturer's data for detector components, shape, materials and dimensions

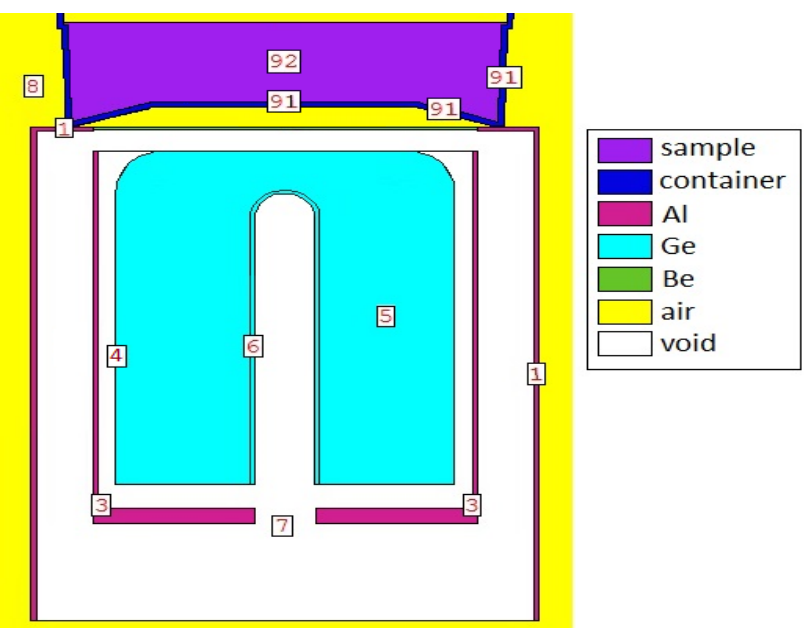

Fig. (3) : MCNP model for the HPGe detector and sample

\section{RESULTS AND DISCUSSION}

Figure (4) shows the results of absolute full energy peak efficiency obtained using MC calculations for the four different soil samples. As shown in the figure, the calculated absolute efficiencies are comparable for all samples at gamma energies above $186.2 \mathrm{keV}$. The average differences between the calculated absolute efficiencies for different samples are ranged between $0.04 \%$ (difference between RGU-1\& MPC soil) and $0.45 \%$ (difference between RGU-1 and IAEA-375). For law gamma energies the maximum difference between the calculated absolute efficiencies is found to be $51 \%$ at 46.5 $\mathrm{keV}$ (difference between RGU-1 and IAEA-375). The large difference is due to the difference in chemical composition of the selected samples where all the selected samples are mainly soil samples except the IAEA-375 sample which is a sediment sample contains high percentages of heavy elements tha contribute to the attenuation of low energies gamma lines

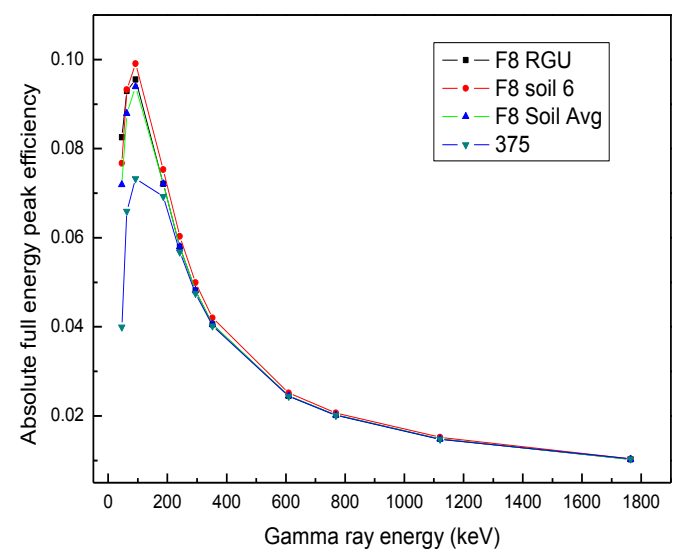

Fig. (4): Absolute full energy obtained using MC calculations for the four different soil samples

\section{CONCLUSIONS}

The effect of variation in the chemical compositions of different samples to be measured using a HPGe detector on the measurement accuracy is investigated. The Monte Carlo simulation technique is used to obtain the detector response due to four different standard soil samples. The samples were assumed to be identical except for chemical compositions and slight variations in densities. It is concluded that, the chemical composition of the sample plays an important role in absolute efficiency calibration of the detectors for gamma energies less than $186.2 \mathrm{keV}$, while at higher energies this effect can be neglected. The study shows that, at gamma energies greater than $186.0 \mathrm{keV}$; samples with different chemical compositions could be measured to estimate their radioactivity based on relative measurements for which other samples with different chemical compositions are used for system calibration. For lower gamma energies, attenuation correction must be carried out in efficiency calibration due to the effect of the different in chemical compositions.

\section{ACKNOWLEDGEMENT}

The author would like to thank Prof. Wael El-gammal the head of safeguards and physical protection department/ENRRA for his support and cooperation in using Mont-Carlo code 


\section{REFERENCES}

[1] Ngo Quang Huy a,n, Do Quang Binh, A semi-empirical approach to analyze the activities of cylindrical radioactive samples using gamma energies from 185 to $1764 \mathrm{keV}$, Applied Radiation and Isotopes 94(2014)82-88.

[2] Browne, E., Firestone, R.B., Shirley, V.S., Table of Radioactive Isotopes. John Wiley and Sons, Inc., New York (1986).

[3] Bé, M.M., Chisté, V., Dulieu, C., Browne, E., Chechev, V., Kuzmenko, N., Kondev, F., Luca, A., Galán, M., Pearce, A., Huang, X., Table of radionuclides, vol. 4. Monographie BIPM-5. Bureau International de Poids and Mesures, Pavillon de Breteuil, (2008), F-92310 SÈVRES.

[4] Paweł Jodłowski, Przemysław Wachniew and Jakub Nowak, Determination of the self-attenuation based on the sample composition in gamma-ray spectrometry of ${ }^{210} \mathrm{~Pb}$ : requirements for the scope of chemical analyses, J Radioanal Nucl Chem (2017) 311:1511-1516, DOI 10.1007/s10967-016-5054-4.

[5] Debertin K, Ren J, Measurement of activity of radioactive samples in Marinelli beakers. Nucl Instr. Method Phys, (1989), Res A 278:541-549

[6] A. Tedjani, C. Mavon, A. Belafrites, D. Degrelle, D. Boumala, D. Rius, J.-E.Groetz , Well GeHP detector calibration for environmental measurements using reference materials, Nuclear Instruments and Methods in Physics Research Section A: Accelerators, Spectrometers, Detectors and Associated Equipment, Elsevier, (2016), 838, pp.12-17.

[7] X-5 Monte Carlo Team, MCNP - A general Monte Carlo N Particle Transport Code, Version 5, Volume I: Overview and theory. LA-UR-03-1987 (Revised 10/3/05), April 24; (2003).

[8] X-5 Monte Carlo Team, MCNP - A general Monte Carlo N Particle Transport Code, Version 5, Volume II: User's guide, LA-CP-03-0245 (Revised 10/3/05), April 24; (2003).

[9] IAEA AQCS Catalogue for reference materials and inter-comparison exercises, (1998/1999), IAEA, Vienna.

[10] Preparation and certification of IAEA gamma-ray spectrometry reference materials RGU-1, RGTh-1 and RGK-1, IAEA/RL/148, (1987).

[11] Zhongtang Wang, Guosheng Yang, Jian Zheng, Liguo Cao, Haijun Yu, Yanbei Zhu, Keiko Tagami1, Shigeo Uchida, Effect of ashing temperature on accurate determination of plutonium in soil samples, Supporting information, Anal. Chem. (2015), 87, 5511-5515. 